\title{
FONTES DE NITROGÊNIO E CAULE DECOMPOSTO DE Mauritia flexuosa NA NODULAÇÃO E CRESCIMENTO DE Enterolobium contortsiliquum ${ }^{1}$
}

Waldeídes Castro Sousa², Rafaela Simão Abrahão Nóbrega ${ }^{3}$, Júlio César Azevedo Nóbrega ${ }^{4}$, Danúbia Rejane Silva Brito ${ }^{5}$ e Fatima Maria Souza Moreira ${ }^{6}$

\begin{abstract}
RESUMO - Avaliaram-se fontes de nitrogênio (N) e proporções de caule decomposto de buritizeiro (Mauritia flexuosa L.f.) na nodulação, crescimento e nos índices biométricos das mudas de tamboril [Enterolobium contortsiliquum (Vell.) Morong] na região sudoeste do Piauí. O delineamento experimental foi inteiramente casualizado em esquema fatorial $3 \times 5$, com cinco repetições. Foram testadas três fontes de $\mathrm{N}$ (N-mineral, $\mathrm{N}$ do substrato e inoculação com a estirpe Bradyrhizobium elkanii BR 4406) e cinco proporções de caule decomposto de buritizeiro:solo (v/v, \%): 0: 100; 10: 90; 20: 80; 40: 60; 80: 20. A emergência das plântulas foi avaliada diariamente até o décimo terceiro dia após a semeadura. Aos 80 dias, as mudas foram coletadas para as determinações da nodulação, do crescimento e dos índices biométricos. As mudas que foram cultivadas com os substratos contendo caule decomposto de buritizeiro apresentaram maior crescimento e nodulação, em relação às que foram cultivadas no substrato 0: 100 (caule decomposto de buritizeiro: solo). A obtenção de máximo Índice de Qualidade de Dickson foi com 48: 52 (caule decomposto de buritizeiro: solo), sendo, portanto, esta a proporção recomendada para a produção de mudas. Com relação às fontes de nitrogênio, a estirpe BR 4406 não foi eficiente em promover ganhos no teor de nitrogênio e matéria seca da parte aérea, em relação ao tratamento com $\mathrm{N}$-mineral. As populações nativas de bactérias diazotróficas presentes no substrato que não recebeu N-mineral e nem inoculação foram capazes de nodular eficientemente o tamboril, uma vez que promoveram acréscimos no teor de nitrogênio e matéria seca da parte aérea equivalentes ao tratamento adubado com N-mineral.
\end{abstract}

Palavras-chave: Inoculação; Bactérias fixadoras de $\mathrm{N}_{2}$; Adubação nitrogenada.

\section{NITROGEN SOURCES AND Mauritia flexuosa DECOMPOSED STEM ON NODULATION AND GROWTH OF Enterolobium contortsiliquum}

\begin{abstract}
Nitrogen sources ( $N$ ) and proportions of decomposed stem from 'buritizeiro' (Mauritia flexuosa L.f.) on nodulation, growth and biometric indexes of 'tamboril' [Enterolobium contortsiliquum (Vell.) Morong] seedlings were evaluated in the Southwestern region of Piauí State, Brazil. The experimental design was a completely randomized factorial $3 \times 5$, with five replications. Three sources of $N$ were tested (mineral $N$ fertilization, $N$ in the substrate, inoculation with the strain Bradyrhizobium elkanii BR 4406), with five proportions of "buritizeiro" decomposed stem: soil (v/v, \%): 0: 100; 10: 90; 20: 80; 40: 60; 80: 20. Seedling emergence was evaluated daily until the thirteenth day after sowing. At 80 days, seedlings were collected for determining biometric indexes and nodulation. The seedlings grown in substrates containing "buritizeiro" decomposed stem showed higher growth and nodulation compared to those grown on the substrate 0: 100 (stem decomposed of "buritizeiro": soil). Maximum Dickson Index of Quality was obtained with the proportion 57: 43. Thus, we recommend this proportion of waste compost and soil for the production of "tamboril" seedlings. Regarding
\end{abstract}

\footnotetext{
${ }^{1}$ Recebido em 06.06.2012 aceito para publicação em 03.09.2013

${ }^{2}$ Graduação na Engenharia Florestal pela Universidade Federal do Piauí, PI, Brasil. E-mail: <waldeidescastro@hotmail.com>.

${ }^{3}$ Universidade Federal do Recôncavo da Bahia, Centro de Ciências Agrárias, Ambientais e Biológicas, BA, Brasil. E-mail: <rafaela.nobrega@gmail.com>.

${ }^{4}$ Universidade Federal do Piauí, Campus Professora Cinobelina Elvas. E-mail: <jcanobrega@gmail.com>.

${ }^{5}$ Programa de Pós-Graduação em Ciências Florestais na Universidade Federal de Campina Grande,UFCG, Brasil. E-mail: <danubiarejane@hotmail.com>.

${ }^{6}$ Departamento de Ciência do Solo da Universidade Federal de Lavras,UFLA, MG, Brasil. E-mail: <fmoreira@dcs.ufla.br>.
} 
to nitrogen sources, strain BR 4406 was not effective in promoting gains in nitrogen content and shoot dry matter, compared to the treatment with mineral- $N$. The native populations of diazotrophic bacteria present on the substrate, which did not receive mineral-N neither inoculation, could efficiently nodulate "tamboril" since they led to an increase in the nitrogen content and on shoot dry matter, similar to the observed on seedlings treated with mineral $N$.

Keywords: Inoculation; Nitrogen fixing bacteria; Mineral N fertilization.

\section{INTRODUÇÃO}

A produção de mudas florestais é uma das etapas mais importantes para o estabelecimento de povoamentos com espécies nativas, seja para programas de reflorestamento, plantios conservacionistas e revegetação de áreas degradadas. Entretanto, fatores como o tipo de recipiente, substrato de cultivo, adubação, tratos culturais (CRUZ et al., 2006; MARQUES et al., 2006 a; b; NÓBREGA et al., 2007; NÓBREGA et al., 2008 a; b; SCALON et al., 2011) e uso de inoculantes bacterianos são importantes para se obter mudas de qualidade.

O substrato deve apresentar características adequadas, visto que estas definem o vigor, sanidade e estado nutricional das mudas. Assim, é imprescindível fazer a escolha correta dos seus componentes, de acordo com a espécie a ser cultivada. Nesse sentido, a utilização de terra de subsolo para compor substratos de espécies florestais constitui uma prática comum para a produção de mudas, por ser economicamente viável e estar sempre disponível. Por ser este material, na maioria das vezes, pobre em matéria orgânica e em nutrientes, a utilização de subprodutos regionais oriundos de atividades agrícolas para enriquecê-lo, pode ser uma alternativa. O caule decomposto de buritizeiro, conhecido popularmente como "paú de buriti”, tem grande disponibilidade na região sudoeste do Piaú e corresponde a um produto natural originado do caule decomposto do buritizeiro (Mauritia flexuosa L.f.), que apresenta elevado teor de matéria orgânica (SILVA, 2012).

Em áreas degradadas, o nitrogênio é um dos nutrientes que se encontra em baixos teores e se mostra limitante ao crescimento e produção florestal. As leguminosas apresentam uma vantagem competitiva em relação à aquisição desse nutriente, pois têm capacidade de estabelecerem simbiose com bactérias diazotróficas. Portanto, elas são importantes sob o ponto de vista ecológico e econômico, podendo dispensar total ou parcialmente os fertilizantes nitrogenados (SALVAGIOTTI et al., 2008; XAVIER et

Revista Árvore, Viçosa-MG, v.37, n.5, p.969-979, 2013 al., 2008; SILVA et al., 2009), contribuindo para viabilizar reflorestamentos, principalmente em áreas degradadas (SANTOS et al., 2001) e minimizar possíveis impactos ambientais decorrentes da utilização destes insumos.

Apesar da importância da fixação biológica para a sustentabilidade dos ecossistemas, há uma carência de pesquisas objetivando avaliar a eficiência de estirpes recomendadas para as espécies arbóreas leguminosas em diferentes condições edafoclimáticas brasileiras. Por outro lado, essa temática é amplamente explorada para as espécies de interesse agronômico como soja (HUNGRIA et al., 2006), feijão caupi (COSTA et al., 2011; ALMEIDA et al., 2010; SOARES et al., 2006; LACERDA et al., 2004,), em que há trabalhos mostrando a adaptabilidade e competitividade das estirpes às diferentes condições edafoclimáticas, confirmando ou não sua eficiência para determinada região.

O tamboril (Enterolobium cortortisiliquum (Vell.) Morong), Mimosaceae, é uma espécie que ocorre no ecótono entre a caatinga e o cerrado do sudoeste do Piauí. Por ser uma leguminosa nodulífera e que possui inoculante aprovado pelo Ministério da Agricultura Pecuária e Abastecimento (BRASIL, 2011), a produção de mudas inoculadas pode propiciar uma vantagem para se estabelecer no campo, devido à aquisição de $\mathrm{N}$ através da fixação biológica. Pesquisas relatam também que essa espécie pode ser promissora para recuperação de solos degradados (TRANINN et al., 2001).

Neste contexto, o objetivo deste estudo foi avaliar o efeito de fontes de nitrogênio (N-mineral, $\mathrm{N}$ do substrato e inoculação com estirpe de Bradyrhizobium BR 4406, aprovada pelo MAPA) e proporções de caule decomposto de buritizeiro na nodulação, crescimento e nos índices biométricos das mudas de tamboril.

\section{MATERIAL E MÉTODOS}

O experimento foi conduzido em viveiro da Universidade Federal do Piauí, Campus Bom Jesus,

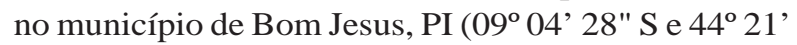
31 "W, com altitude média de $277 \mathrm{~m}$ ).

\footnotetext{
Revista Árvore, Viçosa-MG, v.37, n.5, p.969-979, 2013
} 
Os substratos foram compostos de amostras de Latossolo Amarelo coletadas na camada de 20 a $40 \mathrm{~cm}$ no município de Bom Jesus, PI, acrescidas de caule decomposto de buritizeiro originado naturalmente da decomposição do caule da palmeira do buritizeiro (Mauritia flexuosa) proveniente do município de Palmeira do Piauí, PI. As secagens do caule decomposto do buritizeiro e do solo foram feitas em ambiente natural, espalhando os materiais sobre uma lona plástica, os quais foram passados em peneira de $4 \mathrm{~mm}$, misturados e acondicionados em sacos plásticos com volume para $1 \mathrm{dm}^{-3}$. Amostras dos substratos foram coletadas para análise química, utilizando os métodos compilados pela Embrapa (1997), cujos resultados são apresentados na Tabela 1.

O delineamento experimental foi inteiramente casualizado em esquema fatorial 3x5 com cinco repetições. Foram testadas três fontes de N: N-mineral (150 g de $\mathrm{N}$ como uréia para $1 \mathrm{~m}^{3}$ de solo), $\mathrm{N}$ do substrato e inoculação com estirpe de Bradyrhizobium elkanii BR 4406, e cinco proporções de caule decomposto de buritizeiro:solo (v/v, \%): 0:100; 10:90; 20:80; 40:60; 80:20.

As sementes de tamboril foram previamente tratadas com ácido sulfúrico, por 30 minutos, em seguida lavadas em água corrente (AQUINO et al., 2009) e imersas em água destilada por meia hora. Semearam-se três sementes por saco plástico. No instante da semeadura, as sementes foram inoculadas com $10^{9}$ células $\mathrm{g}^{-1}$ de semente em veículo turfoso da estirpe BR 4406 de Bradyrhizobium elkanii, aprovada pelo MAPA (BRASIL, 2011).

A partir do terceiro dia da semeadura foram iniciadas avaliações diárias da emergência que prosseguiram até a germinação mostrar-se constante. Avaliou-se a porcentagem final de germinação e o índice de velocidade de emergência (IVE), empregando a fórmula de Maguire (1962): IVE= åNi/Di, em que o Ni é o número de sementes germinadas, e Di dias após o plantio. Para o IVE, observou-se o número de sementes emergidas do primeiro ao décimo terceiro dia após a semeadura.

Após 13 dias, foi feito o desbaste deixando uma planta por saco plástico. Após 80 dias da semeadura cinco mudas de cada tratamento foram coletadas aleatoriamente para a realização das avaliações dos parâmetros morfológicos. O diâmetro do caule (D) foi medido com um paquímetro de precisão de $0,05 \mathrm{~cm}$, e a altura da parte aérea $(\mathrm{H})$ com régua, considerando-se como padrão a gema terminal (meristema apical). A matéria seca de parte aérea (MSPA) e da raiz (MSR) foram mensuradas através das pesagens das partes vegetais, após a secagem em estufa a $65^{\circ} \mathrm{C}$ por 72 h até obter o peso constante. A parte aérea foi triturada em um moinho Willey TE-650, para determinar o N total através do método semi-micro Kjeldahl. O Índice de Qualidade de Dickson foi calculado pela fórmula MST/(H/D) + (MSPA/MSR), sendo H em cm e D em mm (DICKSON et al., 1960). O número de nódulos (NN) foi avaliado

Tabela 1 - Caracterização química das amostras de solos com adubação nitrogenada (fonte ureia) e sem adubação nitrogenada e diferentes proporções de caule decomposto de buritizeiro (Mauritia flexuosa L.), para produção de mudas de Enterolobium contortisiliquum (Vell.) Morong.

Table 1 - Chemical characterization of soil samples with nitrogen fertilizer (urea source) and without nitrogen fertilization and different proportions of decomposed stem of buritizeiro (Mauritia flexuosa L.) for the production of Enterolobium contortsiliquum (Vell.) Morong seedlings.

\begin{tabular}{|c|c|c|c|c|c|c|c|c|}
\hline & $\begin{array}{c}\text { Substrato V/V } \\
\text { (solo:caule decomposto } \\
\text { de buritizeiro) }\end{array}$ & $\mathrm{pH}$ & $\begin{array}{l}\mathrm{Ca}^{2+}+\mathrm{Mg}^{2+} \\
\quad\left(\mathrm{cmol}_{\mathrm{c}} \mathrm{dr}\right.\end{array}$ & $\begin{array}{l}\mathrm{Al}^{3+} \\
-3)\end{array}$ & $\mathrm{H}+\mathrm{Al}$ & $\begin{array}{l}\mathrm{P} \\
(\mathrm{m}\end{array}$ & $\begin{array}{l}\mathrm{K}^{+} \\
\left.\mathrm{m}^{3}\right)\end{array}$ & $\begin{array}{c}\text { matéria orgânica } \\
\text { dag kg-1 }\end{array}$ \\
\hline \multirow{5}{*}{ Com adubação } & $0+100$ & 4,4 & 5,2 & 0,3 & 2,9 & 3 & 6,0 & 1,3 \\
\hline & $10+90$ & 4,5 & 6,3 & 0,2 & 2,9 & 15 & 54,4 & 2,5 \\
\hline & $20+80$ & 4,8 & 7,1 & 0,1 & 2,6 & 22 & 66,0 & 4,6 \\
\hline & $40+60$ & 5,4 & 8,0 & 0,1 & 1,9 & 27 & 89,3 & 5,0 \\
\hline & $80+20$ & 5,8 & 10,7 & 0,0 & 1,7 & 34 & 100,0 & 5,3 \\
\hline \multirow{5}{*}{ Sem adubação } & $0+100$ & 4,5 & 5,8 & 0,4 & 2,9 & 2 & 5,3 & 1,2 \\
\hline & $10+90$ & 4,6 & 6,4 & 0,3 & 2,9 & 10 & 27,4 & 2,8 \\
\hline & $20+80$ & 5,0 & 6,7 & 0,1 & 2,6 & 18 & 64,9 & 3,7 \\
\hline & $40+60$ & 5,2 & 7,9 & 0,1 & 2,1 & 24 & 80,5 & 4,8 \\
\hline & $80+20$ & 6,5 & 11,0 & 0,0 & 1,1 & 38 & 107,0 & 6,3 \\
\hline
\end{tabular}


por meio de contagem dos mesmos, destacando-os das raízes das mudas, em seguida pesados para obter o peso fresco, depois colocados em estufa, à $65^{\circ} \mathrm{C}$ por 72 h, para obter o até obter o peso constante.

Os resultados das variáveis foram submetidos às análises de variância, teste de média Scott Knott 5\% para as fontes de $\mathrm{N}$, que caracterizaram os tratamentos qualitativos e de regressão polinomial para as proporções de caule decomposto de buritizeiro (tratamentos quantitativos). Para a avaliação da interação entre as fontes de $\mathrm{N}$ e proporções de caule decomposto de buritizeiro, houve o desdobramento das fontes de $\mathrm{N}$ (variável dependente) dentro das proporções de caule decomposto (variável independente). O programa estatístico utilizado foi o SISVAR 4.2 (FERREIRA, 2000).

\section{RESULTADOS}

A porcentagem de emergência das sementes de tamboril foi relativamente alta, atingindo média acima de $70 \%$ em todos os tratamentos, sem diferenças $(p>0,05)$ entre os mesmos. Quanto ao índice de velocidade de emergência (Figura 1 a), houve somente efeito individual e quadrático $(\mathrm{p}<0,05)$ para as proporções de caule decomposto de buritizeiro, com máximo de 0,76 , obtido na proporção estimada de 41:59 (caule decomposto de buritizeiro:solo).

Para a altura (Figura 1 b), variável considerada como medida do potencial de desempenho das mudas no campo verificou-se interação $(p<0,01)$ entre as fontes de $\mathrm{N}$ e proporções de caule decomposto de buritizeiro. A máxima altura ( $\left.80 \mathrm{~cm}_{\text {planta }}{ }^{-1}\right)$ ocorreu no tratamento com N-mineral na proporção estimada de 59:41 (caule decomposto de buritizeiro:solo). O tratamento sem inoculação (N-substrato) proporcionou média estimada de $61 \mathrm{~cm} \mathrm{planta-1}$, na proporção de 60:40 (caule decomposto de buritizeiro:solo) e no tratamento que recebeu inoculação, o comportamento foi linear crescente.

Houve efeitos individuais das fontes de $N(p<0,01)$ e das proporções de caule decomposto de buritizeiro $(\mathrm{p}<0,01)$ para o diâmetro das mudas (Figura $1 \mathrm{c}$ ). Os tratamentos com N-mineral e o sem inoculação (N-substrato) não diferiram apresentando maior diâmetro comparado ao tratamento inoculado. Em relação às proporções de caule decomposto de buritizeiro, o efeito foi quadrático, com o aumento do diâmetro, e máxima média de 5,8 mm planta ${ }^{-1}$, na proporção 61:39 (caule decomposto de buritizeiro:solo).
A relação entre altura sobre diâmetro das mudas foi influenciada pela interação entre os tratamentos ( $<<0,01$ ) (Figura $1 d$ ). As mudas que receberam $N$-mineral apresentaram média máxima $(13,8)$ na proporção estimada de 54:46 (caule decomposto de buritizeiro:solo), e as que não receberam $\mathrm{N}$-substrato e inoculação, a máxima foi de 11,90, obtida na proporção estimada de 48:52 (caule decomposto de buritizeiro:solo). No tratamento inoculado, o comportamento foi linear crescente.

Em relação às massas secas da parte aérea e da raiz, ocorreram efeitos individuais das fontes de $\mathrm{N}$ (Tabela 2) e das proporções de caule decomposto de buritizeiro (Figuras 1 e e f). As médias do tratamento sem inoculação ( $\mathrm{N}$-substrato) e o com $\mathrm{N}$-mineral foram superioras às do tratamento inoculado, comportamento inverso ocorreu para a massa seca da raiz. A máxima produção de massa seca da parte aérea foi de 6,6 g planta $^{-1}$, obtida na proporção de 70:30 (caule decomposto de buritizeiro:solo) e da raiz de 5,08 g planta $^{-1}$, na proporção estimada de 76,3:23,7 (caule decomposto de buritizeiro:solo). Nóbrega et al. (2008 a) trabalhando com composto de lixo e solo em tamboril encontraram maior massa seca da parte aérea na proporção de 60:40 (composto de lixo:solo).

Considerando a relação entre matéria seca da parte aérea sobre a de raiz, detectou-se diferença $(\mathrm{p}<0,01)$ entre as fontes de $\mathrm{N}$ (Tabela 2), uma vez que o tratamento com $\mathrm{N}$-mineral se mostrou mais eficiente atingindo o valor médio de 1,75, sendo o mais próximo de 2,0, sendo este melhor valor considerado por Brissette (1984). Para as mudas de tamboril, a proporção estimada foi 52:48 (caule decomposto de buritizeiro:solo) que proporcionou a máxima de 1,55 (Figura 2 a).

Houve efeito individual das proporções de caule decomposto de buritizeiro para matéria seca total e altura sobre a massa seca da parte aérea (Figuras 2 b e c), com comportamento quadrático e média máxima estimada de 11,6 g planta $^{-1}$, na proporção estimada de 71,5:28,5 (caule decomposto de buritizeiro:solo) e mínima estimada na proporção 58,5:41,5, respectivamente. Segundo Gomes et al. (2002), quanto menor o quociente obtido pela divisão da altura da parte aérea pelo peso de matéria seca da parte aérea, mais rustificada será a muda e maior deverá ser sua sobrevivência no campo. Assim, como houve um decréscimo desse índice à medida que se adicionou caule decomposto de buritizeiro, até a proporção estimada, pode-se demonstrar o efeito benéfico deste resíduo na qualidade da muda. 

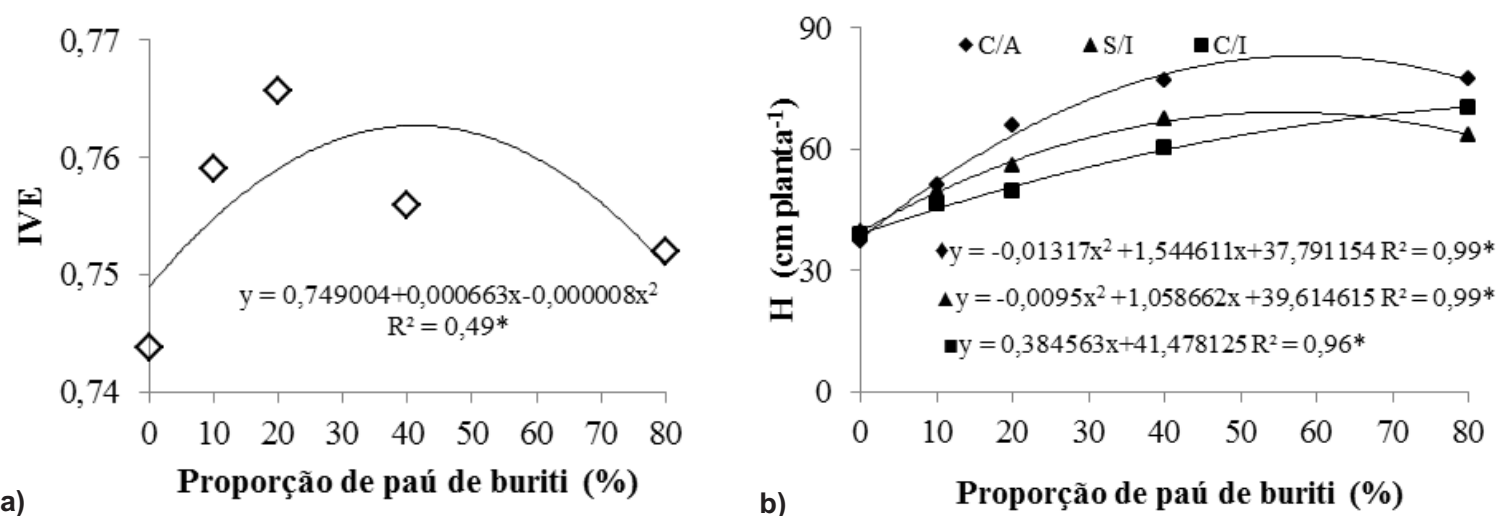

a)

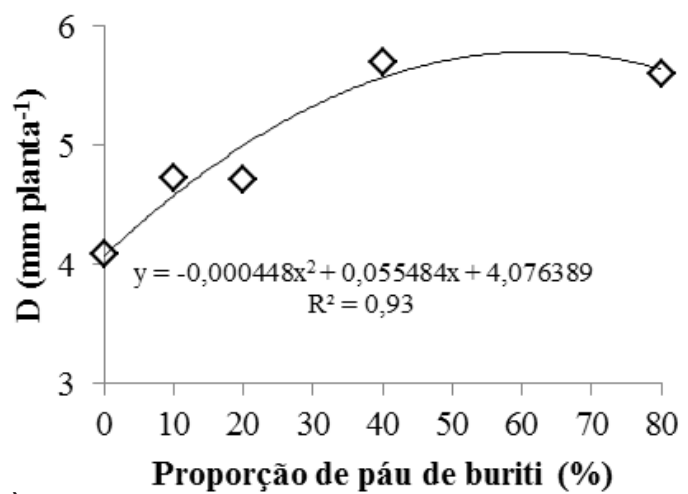

b)

Proporção de paú de buriti (\%)

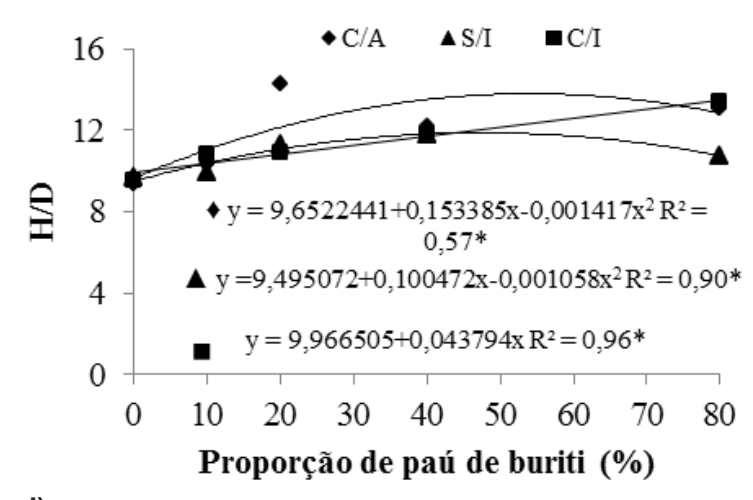

d)

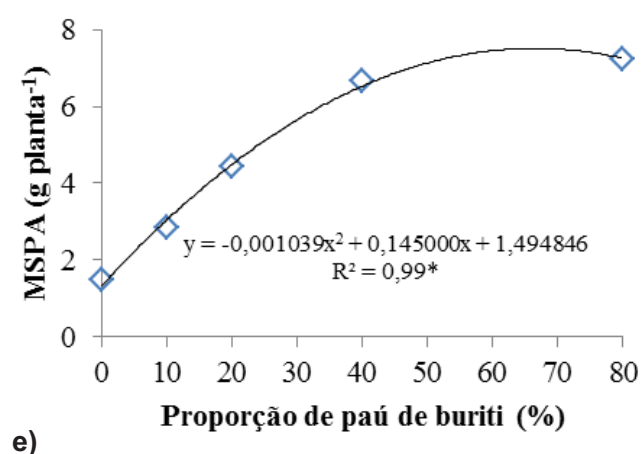

e)

Figura 1 - Regressões dos índices de qualidade para produção de mudas de Enterolobium contortsiliquum (vell.) Morong: (a) índice de velocidade de emergência (IVE) (dos 3 aos 13 dias após a semeadura); (b) altura (H), (c) diâmetro do caule (d); altura sob diâmetro de caule (H/D); (e) matéria seca da parte aérea (MSPA); e (f) matéria seca de raiz (MSR), em função da porcentagem de caule decomposto de buritizeiro (Mauritia flexuosa L.) adicionada ao solo e fontes de nitrogênio [C/A: com adubação nitrogenada mineral, S/I sem inoculação e sem adubação mineral (N-substrato) e C/I: com inoculação].

Figure 1 - Regressions of quality indices for Enterolobium contortsiliquum (vell.) Morong seedlings production: (a) emergence rate index (IES) (from 3 to 13 days after seedling) (b) height $(H),(c)$ stem diameter $(D),(d)$ shoot over stem diameter (H/D), (e) shoot fresh matter (APFM) and (f) root fresh matter (RFM), due to the proportions of decomposed stem of buritizeiro (Mauritia flexuosa $L$.) added to the soil and nitrogen sources [C/A: with mineral nitrogen fertilization, S/I without inoculation and without mineral fertilization ( $N$-substrate) and C/I: with inoculation]. 
Tabela 2 - Diâmetro de caule (D), relação altura sobre diâmetro de caule (H/D), matéria fresca da parte aérea (MSPA), matéria fresca de raiz (MSR), matéria seca total (MST), relação entre altura e matéria seca da parte aérea (H/ MSPA), relação entre matéria seca da parte aérea sobre a matéria seca da raiz (MSPA/MSR), número de nódulos (NN), peso fresco de nódulos (PNF), peso seco de nódulos (PNS), teor de nitrogênio na matéria seca da parte aérea (TN) e índice de qualidade de Dickson (IQD) das mudas de Enterolobium contortsiliquum (vell.) Morong em substratos constituídos de caule decomposto de buritizeiro (Mauritia flexuosa L.), com diferentes fontes de nitrogênio, aos 80 dias de idade.

Table 2 - Stem diameter (D), height over stem diameter ratio (H/D), shoot fresh matter (SFM), root fresh matter (RFM), total dry matter (TDM), height and shoot dry matter ratio (H/DMAP), shoot dry matter over root dry matter ratio ( $S D M / R D M)$, number of nodules (NN), nodule fresh weight (NFW), nodule dry weight (NDW), shoot $N$ concentration (AN) and Dickson quality index (DQI) from Enterolobium contortsiliquum (vell.) Morong seedlings and substrates made of proportions of decomposed stem of buritizeiro (Mauritia flexuosa L.) with different $N$ sources, at 80 days of age.

\begin{tabular}{|c|c|c|c|c|c|c|}
\hline Fonte de $\mathrm{N}$ & $\mathrm{D}$ & $\mathrm{H} / \mathrm{D}$ & MSPA & MSR & MST & H/MSPA \\
\hline & cm planta ${ }^{-1}$ & & & g planta $^{-1}$ & & \\
\hline $\mathrm{C} / \mathrm{I}^{2}$ & $4,66 b^{1}$ & 11,28 a & $3,60 \mathrm{~b}$ & 3,55 a & 7,14 a & $16,71 \mathrm{a}$ \\
\hline $\mathrm{S} / \mathrm{I}$ & 5,15 a & 10,71 a & 4,19 a & 3,87 a & 8,07 a & 15,92 a \\
\hline $\mathrm{C} / \mathrm{A}$ & 5,19 a & 11,85 a & 4,53 a & $2,80 \mathrm{~b}$ & 7,33 a & 16,28 a \\
\hline \multirow[t]{3}{*}{$\mathrm{CV} \%$} & 8,25 & 13,18 & 18,47 & 33,44 & 21,42 & 14,44 \\
\hline & MSPA/MSR & $\mathrm{NN}$ & PNF & PNS & $\mathrm{TN}$ & IQD \\
\hline & & planta $^{-1}$ & \multicolumn{2}{|c|}{ - g planta ${ }^{-1}$} & $\mathrm{mg} \mathrm{g}^{-1}$ & \\
\hline $\mathrm{C} / \mathrm{I}^{2}$ & $1,09 \mathrm{~b}$ & 112,3 a & 1,46 a & $0,24 \mathrm{a}$ & $3,31 \mathrm{~b}$ & $1,72 \mathrm{~b}$ \\
\hline $\mathrm{S} / \mathrm{I}$ & $1,12 \mathrm{~b}$ & 118,8 a & 1,53 a & 0,26 a & 4,08 a & $1,92 b$ \\
\hline $\mathrm{C} / \mathrm{A}$ & 1,75 a & $59,85 \mathrm{~b}$ & 1,37 a & 0,25 a & 3,92 a & $2,24 \mathrm{a}$ \\
\hline $\mathrm{CV} \%$ & 30,92 & 51,59 & 41,32 & 39,56 & 19,79 & 18,93 \\
\hline
\end{tabular}

${ }^{1}$ Médias seguidas da mesma letra, não diferem entre si na coluna pelo teste de Skott Knott $(\mathrm{p}<0,05)$.

${ }^{2} \mathrm{C} / \mathrm{I}$ : com inoculação da estirpe BR 4406, S/I: sem inoculação (N-substrato), C/A: adubação nitrogenada mineral (150 g de $\mathrm{N}$ para 1 m ${ }^{3}$ de solo).

A interação entre as fontes de $\mathrm{N}$ e caule decomposto de buritizeiro não foi significativa para o IQD. Entre as fontes de $\mathrm{N}$, a maior média foi obtida coma fonte $\mathrm{N}$-mineral (Tabela 2). Analisando as proporções do caule decomposto de buritizeiro, a maior média $(2,5)$ ocorreu na proporção estimada de 59: 41 (Figura 2 d).

Verificou-se efeito individual das proporções de caule decomposto sobre a nodulação, e a proporção de 80:20 (caule decomposto de buritizeiro:solo) possibilitou o maior número, peso fresco e seco dos nódulos (Figuras 3 a, b e c). Observa-se o efeito inibitório do tratamento com $\mathrm{N}$-mineral na nodulação natural das mudas, uma vez que este tratamento apresentou o menor número de nódulos.

O teor de $\mathrm{N}$ na matéria seca da parte aérea é uma avaliação de grande importância para se avaliar a eficiência de bactérias diazotróficas simbióticas em fixar nitrogênio. Em relação a essa variável, efeito individual das fontes de $\mathrm{N}$ e das proporções de caule decomposto de buritizeiro (Figura 3 d) foi observado. Para as proporções de caule decomposto de buritizeiro, a resposta foi quadrática e o teor de $\mathrm{N}$ máximo (4,2 $\left.\mathrm{mg} \mathrm{g}^{-1}\right)$ foi obtido na proporção estimada de 48:52 (caule decomposto de buritizeiro:solo).

\section{DISCUSSÃO}

As sementes de E. contortisiliquum apresentam dormência causada pela impermeabilidade do tegumento, e há relatos delas apresentarem alteração da \% de emergência, quando cultivadas em solo, solo + esterco bovino e solo + esterco bovino + casca de arroz carbonizada (ARAÚJO, SOBRINHO, 2011). No presente trabalho, as sementes foram tratadas com ácido sulfúrico, conforme sugerido por Aquino et al. (2009), o que provavelmente, contribuiu para que as diferenças existentes entre os substratos não causassem efeito na \% de emergência.

O índice de velocidade de emergência das sementes de tamboril foi menor nos substratos com porcentagem menor que $40 \%$ de caule decomposto de buritizeiro. Segundo Araújo e Sobrinho (2011), o melhor índice das sementes de tamboril foi obtido nos substratos constituídos de solo + esterco bovino e solo + casca 
de arroz carbonizada e este desempenho foi atribuído ao substrato que reteve a água na quantidade adequada. De acordo com as análises químicas dos substratos (Tabela 1), aqueles com menor nível de matéria orgânica proporcionaram menor índice de velocidade de emergência. Esses resultados devem estar relacionados a menores taxas de retenção de água e baixa porosidade dos substratos, corroborando Scalon et al. (2011).

Devido ao acréscimo de nutrientes, promovido pela adição do caule decomposto de buritizeiro ao solo (Tabela 1), as mudas apresentaram maior altura, em relação às cultivadas nos substratos 0:100 (caule decomposto de buritizeiro; solo) e N-mineral. A adição de $\mathrm{N}$ estimulou o crescimento em altura do tamboril, assim como relatado por Marques et al. (2006 a), que estudando o efeito de fontes e proporções de nitrogênio sobre o crescimento inicial e qualidade de mudas de jacarandá-da-bahia (Dalbergia nigra (Vell.) Fr. All. Ex Benth.), encontraram maiores alturas das mudas que foram cultivadas na fonte nitrogenada mineral.

Ressalta-se a importância do caule decomposto de buritizeiro como fornecedor de nutrientes e matéria

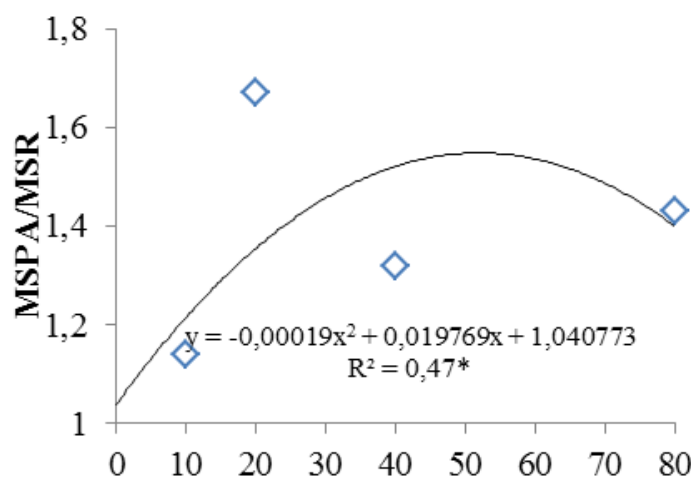

a)

Proporção de paú de buriti (\%)

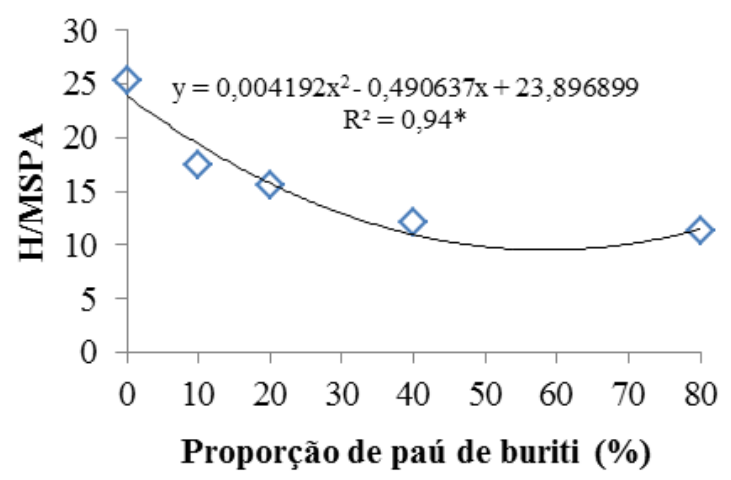

c)
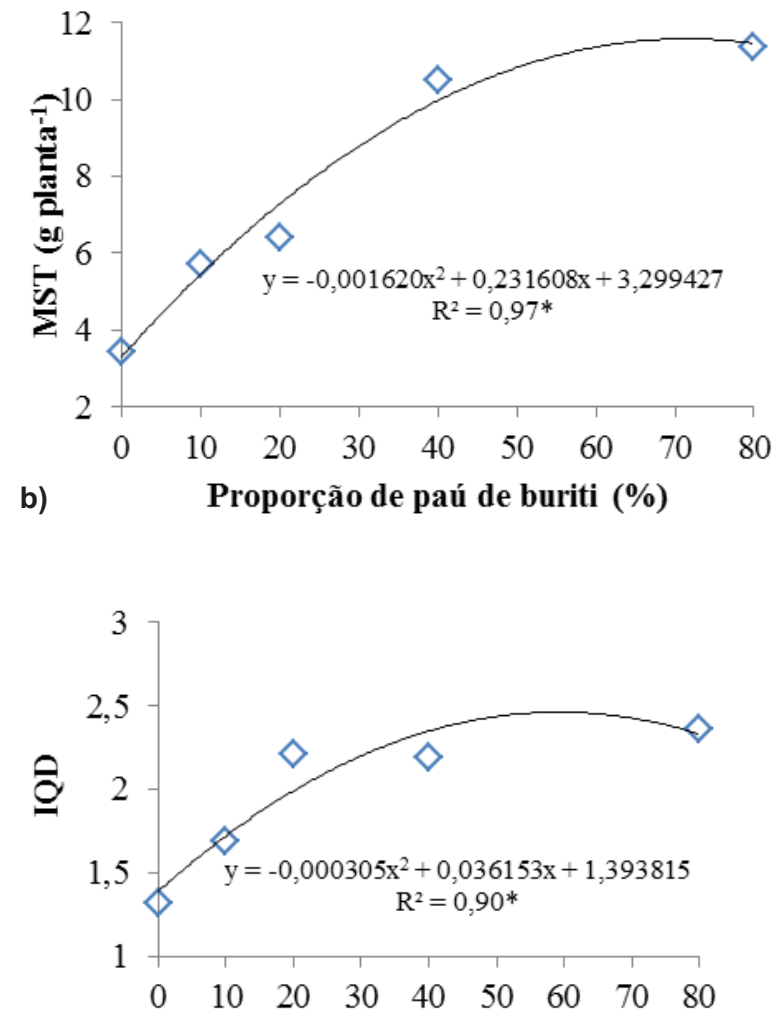

Proporção de paú de buriti (\%)

d)

Figura 2 - Regressões dos índices de qualidade para produção de mudas de Enterolobium contortsiliquum (vell.) Morong: (a) relação entre matéria seca da parte aérea/ matéria seca de raiz (MSPA/MSR); (b) matéria seca total (MST); (c) relação entre altura da parte aérea e matéria seca da parte aérea (H/MSPA); e (d) índice de qualidade de Dickson (IQD) aos 80 dias, cultivadas com diferentes proporções de caule decomposto de buritizeiro (Mauritia flexuosa L.) e amostras de solo.

Figure 2 - Regressions of quality indices for Enterolobium contortsiliquum (vell.) Morong seedlings production: (a) relation between shoot dry matter/ root dry matter (APDM/RDM), (b) total dry matter (TDM, (c) relation between shoot height and shoot dry matter (H/APDM) and (d) Dickson quality index (DQI), at 80 days, cultivated with different proportions of decomposed stem of buritizeiro (Mauritia flexuosa L.) and soil samples. 
orgânica em substratos constituídos de solo (Tabela 1), uma vez que proporcionou aumento de variáveis de crescimento, inclusive proporcionando aumento do diâmetro, com médias semelhantes às verificadas por Nóbrega et al. (2008 a), que cultivaram E. contortisiliquum em diferentes proporções de composto de lixo urbano e solo e obtiveram média máxima de D de 5,6 mm planta ${ }^{-1}$.

As produções de matéria seca de parte aérea e raiz são consideradas boas variáveis para a avaliação da qualidade de mudas (BERNARDINO et al., 2005).
Analisando-as, pode-se verificar que a proporção estimada de 66:34 (caule decomposto de buritizeiro:solo) possibilitou as maiores médias. Para as mudas cultivadas somente com o substrato 0:100 (caule decomposto de buritizeiro:solo), essas variáveis foram as que apresentaram menores médias, refletindo as condições menos férteis do substrato de cultivo (Tabela 1) e também a capacidade responsiva do tamboril a adição de nutrientes, corroborando outros trabalhos (NÓBREGA et al., 2008 a; ARAÚJO; SOBRINHO, 2011).

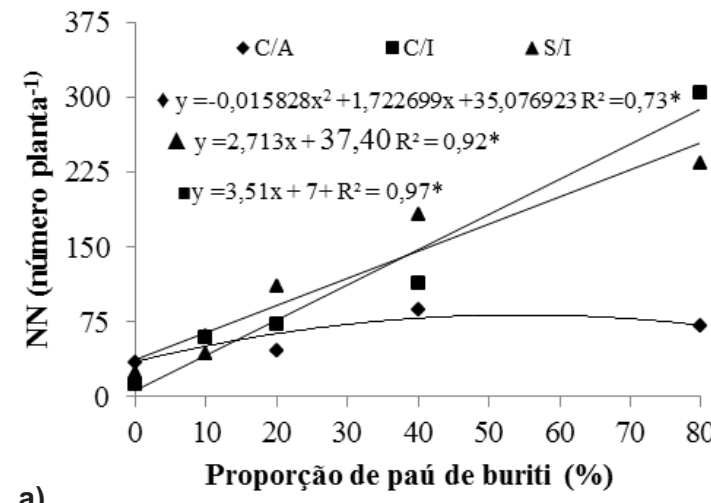

a)

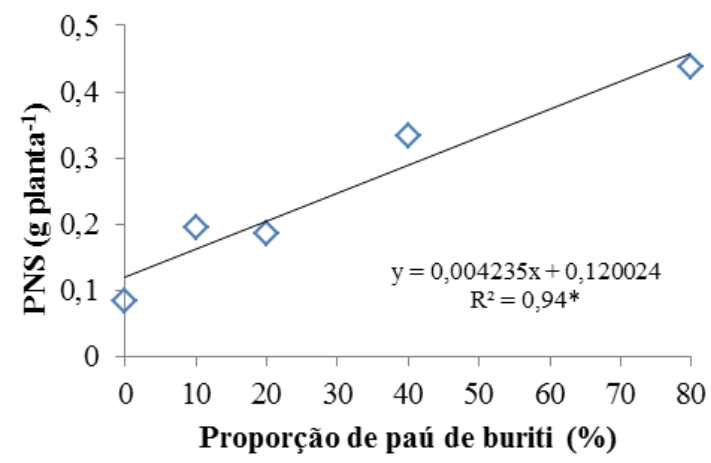

c)

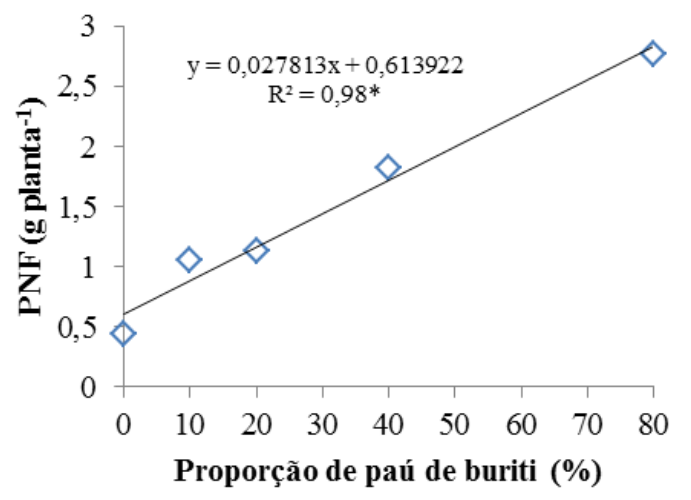

b)

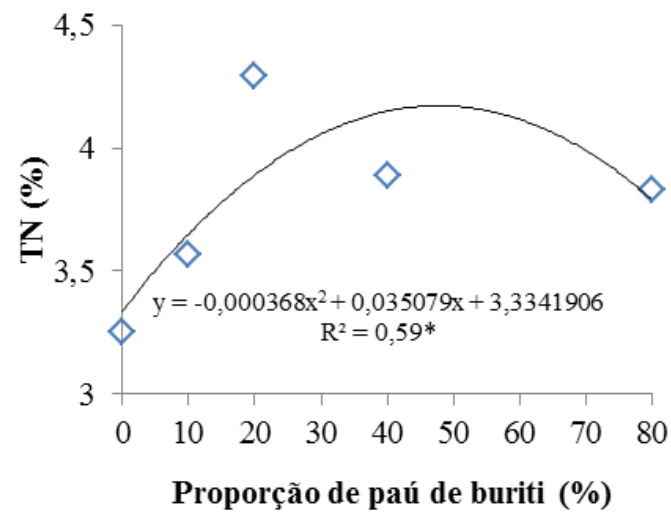

d)

Figura 3 - Regressões dos índices de qualidade para produção de mudas de Enterolobium contortsiliquum (vell.) Morong, em função da proporção de caule decomposto de buritizeiro (Mauritia flexuosa L.) adicionada ao solo: (a) número de nódulos (NN); (b) peso dos nódulos frescos (PNF); (c) peso dos nódulos secos; e (d) teor de nitrogênio na parte aérea [C/A: com adubação nitrogenada mineral, S/I sem inoculação e sem adubação mineral (N-substrato) e C/I: com inoculação].

Figure 3 - Regressions of quality indices for Enterolobium contortsiliquum (vell.) Morong seedlings production, due to the proportions of decomposed stem of buritizeiro (Mauritia flexuosa L.) added to the soil; (a) number of nodules (NN), (b) weight of fresh nodules (WFN); (c) weight of dry nodules and (d) amount of nitrogen in the shoots [C/A: with mineral nitrogen fertilization, $\mathrm{S} / \mathrm{I}$ without inoculation and without mineral fertilization ( $N$-substrate) and C/I: with inoculation].

Revista Árvore, Viçosa-MG, v.37, n.5, p.969-979, 2013 
As mudas cultivadas com os substratos contendo caule decomposto de buritizeiro também apresentaram maiores índices biométricos, em relação às que foram cultivadas sem a adição desse material (Figuras 1, 2 e 3). Para o índice de qualidade de Dickson, a proporção estimada de 59:41 (caule decomposto de buritizeiro:solo) promoveu acréscimo, em relação ao substrato 0:100 (páu de buritizeiro:solo) (Figura 2d). Isto pode ser atribuído não só ao efeito químico relacionado à disponibilidade de nutrientes (Tabela 1), como também ao efeito físico que a adição de material orgânico proporciona no substrato, como menor densidade do mesmo, maiores porosidade total, aeração e retenção de água. Como é de fácil aquisição e disponibilidade na região sudoeste do Piauí, apresenta-se como alternativa para adubar substratos constituídos de solo.

Analisando as variáveis relacionadas à interação entre planta e simbionte, o número de nódulos para o tamboril foi influenciado pelas fontes de N (Tabela 2). Os tratamentos com e sem inoculação apresentaram resultados semelhantes e o com adubação nitrogenada produziu menor número na raiz. Na literatura são vários os estudos que comprovam a inibição da nodulação por proporções de $\mathrm{N}$ aplicadas na forma mineral (SALVAGIOTTI et al., 2008; SILVAet al., 2009). Já espécies como sabiá (Mimosa caesalpiniaefolia Benth.) apresentaram incremento na nodulação quando cultivadas em substratos adubados com dose de $134 \mathrm{mg} \mathrm{dm}^{-3}$ de N mineral (MARQUES et al., 2006 b) e mudas de Sesbania virgata foram capazes de nodular quando cultivadas em substrato rico em matéria orgânica (NÓBREGA et al., 2008 b), assim como as mudas de tamboril do presente estudo.

As mudas cultivadas nos tratamentos sem inoculação (N-substrato) e com N-mineral apresentaram teores de $\mathrm{N}$ na parte aérea superiores ao tratamento que recebeu somente a inoculação (Tabela 2). Fatores abióticos tais como: temperatura, $\mathrm{pH}$ do solo, umidade, disponibilidade de nutrientes, como também os bióticos como por exemplo a competição da estirpe inoculante com as populações nativas de bactérias diazotróficas indígenas interferem nas etapas da simbiose entre hospedeiro e o microsimbionte. A competição de cepas exóticas com as indígenas, pelos sítios de infecção na raiz podem ocasionar diminuição na eficiência da fixação de $\mathrm{N}_{2}$ para a planta, uma vez que os nódulos serão constituídos de cepas de eficiência variável (COSTA et al., 2011). Isto constitui, na maioria das vezes, uma barreira para o estabelecimento das estirpes inoculantes. Como o tamboril é comum na região, naturalmente as populações nativas de bactérias diazotróficas simbióticas já são adaptadas às condições edáficas e climáticas, sendo competitivas e eficientes em estabelecer a simbiose com a espécie. Dessa forma, a estirpe recomendada não foi eficiente em promover ganhos de matéria seca da parte aérea nas mudas de tamboril cultivadas em substratos constituídos de solos da região sudoeste do Piauí.

A partir da análise da interação entre fonte de $\mathrm{N}$ e proporções de caule decomposto de buritizeiro pode-se verificar que as mudas cultivadas com os substratos contendo caule decomposto de buritizeiro apresentaram maior crescimento e nodulação, em relação às que foram cultivadas no substrato 0:100 (caule decomposto de buritizeiro: solo). A obtenção de máximo índice de qualidade de Dickson foi com 48:52 (caule decomposto de buritizeiro: solo), sendo, portanto, esta a proporção recomendada para a produção de mudas. Com relação às fontes de nitrogênio, a estirpe BR 4406 não foi eficiente em promover ganhos no teor de nitrogênio e matéria seca da parte aérea, em relação ao tratamento com $\mathrm{N}$-mineral. As populações nativas de bactérias diazotróficas presentes no substrato que não recebeu $\mathrm{N}$-mineral e nem inoculação foram capazes de nodular eficientemente o tamboril, uma vez que promoveram acréscimos no teor de nitrogênio e matéria seca da parte aérea equivalentes ao tratamento adubado com $\mathrm{N}$-mineral.

\section{AGRADECIMENTOS}

Os autores agradecem ao Conselho Nacional de Desenvolvimento Científico e Tecnológico (CNPq), Ministério da Agricultura Pecuária e Abastecimento (MAPA) e a Secretaria de Desenvolvimento da Agricultura/SDA pela auxilio financeiro ao projeto. Ao Programa Nacional de Cooperação Acadêmica (PROCAD) que possibilitou o intercâmbio entre a Universidade Federal do Piauí/CPCE com a Universidade Federal de Lavras (UFLA), Departamento de Ciência do Solo (DCS). Ao CNPq pela bolsa de produtividade em pesquisa de F.M.S.Moreira.

\section{REFERÊNCIAS}

ALMEIDA, A. L. G. et al. Produtividade do feijãocaupi cv BR 17 Gurguéia inoculado com bactérias diazotróficas simbióticas no Piauí. Agrária, v.5, n.3, p.364-369, 2010.

Revista Árvore, Viçosa-MG, v.37, n.5, p.969-979, 2013 
AQUINO, A. F. M. A. G. Superação de dormência de orelha-de negro [Enterolobium contortsiliquum (vell.) Morong]. Revista Verde de Agroecologia e Desenvolvimento Sustentável, v.4, n.1, p.69-75, 2009.

ARAÚJO, A. P.; PAIVA SOBRINHO, S. Germinação e produção de mudas de tamboril Enterolobium contortsiliquum (vell.) Morong em diferentes substratos. Revista Árvore, v.35, n.3, p.581-588, 2011.

BERNARDINO, D. C. S. et al. Crescimento e qualidade de mudas de Anadenanthera macrocarpa (Benth) Brenan em resposta à saturação por bases do substrato. Revista Árvore, v.29, n.6, p.863-870, 2005.

BRISSETTE, J. C. Summary of discussion about seedling quality. In: SOUTHERN NURSERY CONFERENCES, 1984, Alexandria.

Proceedings... New Orleans: USDA/Forest Service, Southern Forest Experiment Station, 1984. p.127-128.

COSTA, E. M. et al. Nodulação e produtividade de Vigna unguiculata (L.) Walp. por cepas de rizóbio em Bom Jesus, PI. Revista Ciência Agronômica, v.42, n.1, p.1-7, 2011.

CRUZ, C. A. F.; PAIVA, H. N.; GUERRERO, C. R. A. Efeito da adubação nitrogenada na produção de muda de Sete-cascas [Samanea inopinata (Harms) ducke]. Revista Árvore, v.30, n.4, p.537-546. 2006.

DICKSON, A.; LEAF, A.; HOSNER, J. F. Quality appraisal of white spruce and white pene seedling stock in nurseries. Forestry Chronicle, v.36, n.1, p.10-13, 1960.

\section{EMPRESA BRASILEIRA DE PESQUISA} AGROPECUÁRIA - EMBRAPA. Centro Nacional de Pesquisa de Solos. Manual de métodos de análise de solo. 2.ed. Rio de Janeiro: 1997. 212p.

FERREIRA, D. F. Análises estatísticas por meio do SISVAR para Windows 4.0. In: REUNIÃO ANUAL BRASILEIRA DA SOCIEDADE INTERNACIONAL DE BIOMETRIA, 45., 2000, São Carlos. Anais... São Carlos: Universidade Federal de São Carlos, 2000. p.255-258.

Revista Árvore, Viçosa-MG, v.37, n.5, p.969-979, 2013
HUNGRIA, M. et al. Nitrogen nutrition of soybean in Brazil: contributions of biological $\mathrm{N}_{2}$ fixation and $\mathrm{N}$ fertilizer to grain yield.

Canadian Journal of Plant Science, v.86, n.4, p.927-939, 2006.

LACERDA, A. M. et al. Efeito de cepas de rizóbio sobre a nodulação e produtividade do feijão caupi. Revista Ceres, v.51, n.293, p.67-82, 2004.

MAGUIRE, J. D. Speed of germination-aid in selection and evolution for seedlings emergence and vigor. Crop Science, v.2, n.1, p.176-177, 1962.

BRASIL. Ministério da Agricultura, Pecuária e Abastecimento. Diário Oficial da União - Seção 1., Instrução normativa no. 13 de 24 de março de 2011.

MARQUES, V. B. et al. Efeito de fontes e doses de nitrogênio sobre o crescimento inicial e qualidade de mudas de jacarandá-da-bahia (Dalbergia nigra (Vell.) Fr. All. Ex Benth.). Revista Árvore, v.30, n.5, p.725-735, $2006 a$.

MARQUES, V. B. et al. Efeitos de fontes e doses de nitrogênio no crescimento de mudas de sabiá (Mimosa caesalpiniaefolia Benth.). Scientia Forestalis, v.36, n.71, p.77-85, 2006b.

NÓBREGA, R. S. A. et al. Efeito do composto de lixo urbano no crescimento inicial de mudas de Enterolobium contortisiliquum (Vell.) Morong. Scientia Forestalis, v.36, n.79, p.181-189, 2008a.

NÓBREGA, R. S. A. et al. Parâmetros morfológicos de mudas de Sesbania virgata (Caz.) Pers e de Anadenanthera peregrina (L.) cultivadas em substrato fertilizado com composto de lixo urbano. Revista Árvore, v.32, n.3, p.597-607, 2008b.

NÓBREGA, R. S. A. et al. Utilização de biossólido no crescimento inicial de mudas de aroeira (Schinus terebynthifolius Raddi).

Revista Árvore, v.31, n.2, p.239-246, 2007. 
SALVAGIOTTI, F. et al. Nitrogen uptake, fixation and response to fertilizer $\mathrm{N}$ in soybeans: a review. Field Crops Research, v.108, n.1, p.1-13, 2008.

SANTOS, A. C. et al. Gramíneas e leguminosas na recuperação de áreas degradadas: efeitos nas características químicas de solo. Revista Brasileira de Ciência do Solo, v.25, n.4, p.1063-1071, 2001.

SCALON, S. P. Q. et al. Germinação e crescimento de Caesalpinia ferrea Mart. Ex Tul. em diferentes substratos. Revista Árvore, v.35, n.3, p.633639, 2011.

SILVA, E. F. et al. Inoculação do feijoeiro com Rhizobium tropici associada à exsudato de Mimosa flocculosa com diferentes doses de nitrogênio. Bragantia, v.68, n.2, p.443-451, 2009.
SILVA, R. R. S. Substratos e boro para a produção de mudas de maracujazeiro amarelo. 2012. 52f. Dissertação (Mestrado em Solos e Nutrição de Plantas) - Universidade Federal do Piauí, Bom Jesus, 2012.

SOARES, A. L. L. et al. Eficiência agronômica de rizóbios selecionados e diversidade de populações nativas nodulíferas em Perdões (MG). I - Caupi. Revista Brasileira de Ciência do Solo, v.30, n.5, p.795-802, 2006.

TRANNIN, I. C. B. et al. Crescimento e nodulação de Acacia mangium, Enterolobium contortisiliquum e Sesbania virgata em solo contaminado com metais pesados. Revista Brasileira de Ciência do Solo, v.25, n.3, p.743-753, 2001.

XAVIER, T. F. et al. Inoculação e adubação nitrogenada sobre a nodulação e a produtividade de grãos de feijão-caupi. Ciência Rural, v.38, n.7, p.2037-2041, 2008. 
